\title{
"Aggrecanase" activity is implicated in tumour necrosis factor $\alpha$ mediated cartilage aggrecan breakdown but is not detected by an in vitro assay
}

\author{
D J Buttle, A Fowles, M Z Ilic, C J Handley
}

\begin{abstract}
Aims-To develop an in vitro assay for the putative glutamyl endopeptidase, "aggrecanase", which is thought to degrade cartilage aggrecan, and to examine the role of the enzyme in tumour necrosis factor stimulated aggrecan cleavage.

Methods-Aggrecan fragments released by bovine nasal cartilage explants, with and without exposure to tumour necrosis factor $\alpha$, were purified and analysed by western blotting and $\mathrm{N}$-terminal sequencing. Intact bovine aggrecan was incubated with extracts of cartilage, lysed chondrocytes, or cartilage explant conditioned culture medium under a variety of conditions. Deglycosylated aggrecan was incubated with nasal cartilage explants. Proteoglycan breakdown was assessed by metachromatic assay of fragments in culture media, and cleavage of the substrate at the aggrecanase cleavage site was detected and measured using the antibody BC3, which recognises a neoepitope produced by aggrecanase cleavage of aggre-
\end{abstract} can.

Results-Aggrecan fragments generated from explants treated with tumour necrosis factor had $\mathbf{N}$-terminal sequences consistent with cleavage of aggrecan at a restricted number of glutamyl bonds. Aggrecanase generated fragments were found in cartilage explant culture medium and chondrocyte monolayers. However, no aggrecanase activity could be detected in extracts of cartilage, or chondrocytes from which endogenous aggrecan fragments had been removed, under a variety of assay conditions. Deglycosylated aggrecan, added to explant cultures, efficiently inhibited endogenous aggrecan breakdown.

Conclusions-Aggrecanase is active in cartilage and in chondrocyte monolayers, and its action is stimulated by tumour necrosis factor $\alpha$. However, activity due to this enzyme could not be detected in vitro under our assay conditions, although a deglycosylated version of the substrate inhibited aggrecan breakdown in explant cultures.

(F Clin Pathol: Mol Pathol 1997;50:153-159)

Keywords: "aggrecanase"; aggrecan; cartilage; tumour necrosis factor
High concentrations of the aggregating proteoglycan, aggrecan, are required for the normal functioning of cartilage; loss of aggrecan from cartilage, together with its bound water, results in loss of compressive stiffness of the tissue. ${ }^{1}$ Aggrecan is lost from articular cartilage during the development of arthritis, ${ }^{2}$ compromising the correct functioning of the joint and possibly leading to damage to other components of cartilage, such as type II collagen.

Despite over 40 years of research, the mechanisms of aggrecan breakdown are only poorly understood. The process appears to be largely chondrocyte mediated, ${ }^{3}$ wherein the cell responds to catabolic stimuli, such as those produced in response to the proinflammatory cytokines, interleukin (IL) $-1,{ }^{4}$ and tumour necrosis factor (TNF). ${ }^{5}$ Changes in chondrocyte gene expression lead to the manifestation of a catabolic phenotype driven by a putative proteolytic cascade ${ }^{6}$; evidence implicating certain proteolytic enzymes in this cascade has recently been reviewed. ${ }^{7}$ It has been shown, for instance, that inhibitors of matrix metalloproteinases, ${ }^{6-11}$ and of cathepsin B (E.C.3.4.22.1), ${ }^{6}$ can inhibit chondrocyte mediated aggrecan breakdown that has been stimulated by cytokines or retinoic acid.

Aggrecan fragments identified in the synovial fluid of normal bovine knee joints, osteoarthritic human knees, ${ }^{12}$ injured joints, and the joints of patients with acute pyrophosphate arthritis, reactive arthritis, psoriatic arthritis, and juvenile rheumatoid arthritis ${ }^{13}$ have the same N-terminal sequence. The corresponding aggrecan fragments have been isolated from the conditioned culture media of bovine cartilage explants maintained in the presence or absence of IL-1 and retinoic acid, ${ }^{6}{ }^{14-16}$ and from retinoic acid stimulated chondrosarcoma cells. ${ }^{17}$ These fragments appear to be formed by the action of an endopeptidase with specificity for cleavage between glutamic acid and a small aliphatic amino acid. Although the identity of this enzyme remains obscure, it has been referred to as "aggrecanase". ${ }^{18}$ Recent evidence suggests that aggrecanase may be a metalloproteinase, but not one of the known secreted matrix metalloproteinases. ${ }^{11}$ Despite the knowledge that cartilage explants respond to exposure to TNF, as they do to IL- $1,{ }^{45}$ by increasing the rate of proteoglycan breakdown, the $\mathrm{N}$-terminal sequences of aggrecan fragments released as a result of TNF treatment have not been examined. Hence, to date, there is no direct evidence for the involvement of aggrecanase in the TNF mediated catabolic response. 
The $\mathrm{N}$-terminal neoepitope produced by aggrecanase cleavage can be identified by use of the monoclonal antibody BC3. ${ }^{19}$ We have used this antibody in an attempt to identify aggrecanase activity in lysates of cultured chondrocytes, cartilage explants, and explant conditioned culture medium, and have examined the $\mathrm{N}$-terminal sequences of aggrecan fragments produced in response to TNF.

\section{Methods}

Reagents used for tissue culture were supplied by Life Technologies, Paisley, UK. Where reagents are not standard analytical grade their supplier is specified.

\section{CARTILAGE EXPLANT CULTURES}

Bovine nasal septum cartilage explants were prepared and cultured as described previously. ${ }^{20}$ Mediators of proteoglycan degradation were added to these cultures as follows: all-transretinoic acid (Ret), (Sigma Chemical Company, Poole, Dorset, UK) to a final concentration of $1 \mu \mathrm{M}$ from a freshly prepared stock solution in dimethyl sulphoxide ( $\left.\mathrm{Me}_{2} \mathrm{SO}\right)$; recombinant human IL-1 $\alpha$ (rhIL-1 $\alpha$ ) specific activity $5 \times 10^{7} \mathrm{U} / \mathrm{mg}$ (from Dr K Roy, Glaxo, Greenford, UK) and specific activity $1.2 \times 10^{8} \mathrm{U} / \mathrm{mg}$ (from Dr S Dower, Immunex, Seattle, WA, USA) to a final concentration of $0.3 \mathrm{nM}$; or recombinant human $\mathrm{TNF} \alpha$ (rhTNF $\alpha$ ) specific activity $8 \times 10^{7} \mathrm{U} / \mathrm{mg}$ (from Dr E Amento, Genentech Inc, Boulder, CO, USA) to a final concentration of $3 \mathrm{nM}$. Explants with and without rhIL-1 $\alpha$ were cultured for two days, and with or without rhTNF $\alpha$, or Ret, for five days, with a change of medium on day 2 .

\section{CHONDROCYTE CELL CULTURE}

Cartilage from bovine nasal septum or metacarpophalangeal joints was obtained by dissection and all extraneous soft tissue was discarded. The cartilage was diced into pieces of approximately $2 \mathrm{~mm}^{3}$. These were washed in Dulbecco's phosphate buffered saline (DPBS) containing antibiotics (penicillin, $100 \mathrm{U} / \mathrm{ml}$; streptomycin, $100 \mu \mathrm{g} / \mathrm{ml}$; amphotericin $\mathrm{B}, 0.2 \mu \mathrm{g} / \mathrm{ml}$ ). Each $5 \mathrm{~g}$ of cartilage was incubated in $20 \mathrm{ml}$ of $0.25 \%$ trypsin in Dulbecco's modification of Eagle's medium (DMEM) (Life Technologies) for 30 minutes at $37^{\circ} \mathrm{C}$. After washing in DMEM containing $10 \%$ (vol/vol) fetal calf serum (FCS), glutamine $(2 \mathrm{mM})$, and antibiotics, the cartilage was incubated in collagenase from Clostridium butylicum (Sigma), ( $3 \mathrm{mg} / \mathrm{ml}$ ) in serum-containing medium $(20 \mathrm{ml} / 5 \mathrm{~g}$ of tissue) overnight at $37^{\circ} \mathrm{C}$. Any undigested tissue was allowed to settle and the supernatant was decanted into a separate tube. Chondrocytes were recovered by centrifugation $(12.5 \times g)$ and the cell pellet was washed twice in DPBS. After counting, the cells were resuspended in an appropriate volume of medium containing $10 \%$ (vol/vol) FCS and plated at $2 \times 10^{5}$ cells/ $\mathrm{cm}^{2}$ (metacarpophalangeal chondrocytes) or $1.6 \times 10^{5}$ cells $/ \mathrm{cm}^{2}$ (nasal chondrocytes). The high plating densities inhibited cell division and dedifferentiation of the chondrocytes. ${ }^{21}$ Cells were maintained for various lengths of time in culture with a change of medium every three days.

\section{EXTRACTION OF PROTEOGLYCAN FROM}

CARTILAGE

Bovine nasal septum was removed, cleaned and chopped into pieces of approximately으 $2 \mathrm{~mm}^{3}$. The pieces were soaked overnight at room temperature in $0.1 \mathrm{M}$ Tris $/ \mathrm{HCl}, \mathrm{pH} 7.4, \underset{\text { Tे }}{\text { ? }}$ containing $4 \mathrm{M}$ guanidinium chloride and $\Rightarrow$ proteinase inhibitors (1 $\mathrm{mM}$ phenylmethylsulphonyl fluoride, $10 \mu \mathrm{M}$ L-3-carboxy-2,3-들 trans-epoxypropionyl-leucylamido(4-guanidino) $\frac{\bar{\sigma}}{\bar{\omega}}$ butane (E64), $0.1 \mathrm{mM} \mathrm{1,10-phenanthroline,} \overrightarrow{\widetilde{D}}$ and $1 \mu \mathrm{g} / \mathrm{ml}$ pepstatin). Proteoglycan was pre- $\varrho$ cipitated from the extraction mixture by addi-ळ tion of three volumes of ethanol, and recovered $\overrightarrow{0}$ by centrifugation $\left(245 \times g, 4^{\circ} \mathrm{C}\right)$. The pellet was $=$ dissolved in $1 \mathrm{M}$ potassium acetate, $\mathrm{pH} 7.0, \vec{\omega}$ containing proteinase inhibitors, reprecipitated 3 with ethanol, and resuspended in a minimal vol- - . ume of water overnight at $4^{\circ} \mathrm{C}$. The ethanol precipitation was repeated, the pellet washed with. water, and then freeze-dried.

AGGRECAN FRAGMENTS

Cartilage explant culture media containing $\vec{c}$ fragments of aggrecan were freeze-dried.

\section{PROTEOGLYCAN DEGLYCOSYLATION}

The freeze-dried samples, either intact proteoglycan or culture medium containing proteo-o glycan fragments, were resuspended in a minimal volume of deglycosylation buffer $(0.1 \mathrm{M}$ Tris/ $0.1 \mathrm{M}$ sodium acetate, adjusted to $\mathrm{pH} 7.0 \frac{\mathrm{D}}{\mathrm{Q}}$ with $\mathrm{HCl}$ ) and incubated with proteinase-free chondroitin ABC lyase (EC 4.2.2.4) and keratan-sulphate endo-1,4-beta-galactosidase $\underset{T}{\supset}$ (keratanase, endo-betagalactosidase, ECF 3.2.1.103) (ICN Flow, Thame, Oxfordshire, $\mathrm{UK})(1 \mathrm{mU} / \mu \mathrm{g}$ sulphated glycosaminoglycan (sGAG) estimated by a dye-binding assay) ${ }^{22}$ at: $37^{\circ} \mathrm{C}$ until no further sGAG removal was: detected. The deglycosylated material wasoำ washed with three volumes of ethanol, three volumes of $80 \%$ (vol/vol) ethanol, air-dried, and frozen.

ADDITION OF DEGLYCOSYLATED PROTEOGLYCAN N TO EXPLANT CULTURES

Deglycosylated proteoglycan (prepared as above) was suspended in DMEM, and the pro- $\omega$ tein concentration was estimated by the BioRad dye-binding assay. The material was added at concentrations ranging from $0-1.41 \mathrm{mg} / \mathrm{ml} \stackrel{\infty}{-}$ ( $3.5 \mu \mathrm{M}$ assuming an average molecular mass 0 of 400000 for the deglycosylated proteoglycan)웅

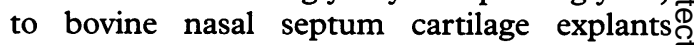
cultured with and without rhIL-1 $\alpha$. The $\underset{\Omega}{\mathbb{Q}}$ cultures were incubated for two days, aftero which released endogenous proteoglycan was assayed with dimethylmethylene blue, ${ }^{22}$ ando fragmentation of the exogenous deglycosylated proteoglycan was assessed by western blotting. 구

IMMUNOBLOTTING

Samples to be analysed by western blots were separated by $4-10 \%$ gradient polyacrylamide gel electrophoresis (PAGE) in the presence of sodium dodecyl sulphate (SDS), ${ }^{23}$ or by 
SDS-PAGE. ${ }^{24}$ Prior to loading, sGAG chains were removed by deglycosylation. Following electrophoresis proteins were transferred on to polyvinylidene difluoride (PVDF) membranes (Millipore, Watford, Hertfordshire, UK) by electroblotting in $10 \mathrm{mM}$ 3-(cyclohexylamino)-1-propanesulphonic acid, $10 \%$ methanol, $\mathrm{pH} 11.0$, for one and a half hours at $250 \mathrm{~mA}$. The membranes were treated with 20 $\mathrm{mM}$ sodium/potassium phosphate, $0.15 \mathrm{M}$ $\mathrm{NaCl}$, pH 7.2, containing $5 \%$ ( $\mathrm{vol} / \mathrm{vol}$ ) horse serum (blocking buffer) for at least four hours. Filters were then incubated with primary antibody, either BC3 (1:1000 dilution) which detects the $\mathrm{N}$-terminal neoepitope generated by aggrecanase action on the aggrecan interglobular domain ${ }^{19}$ or $3 \mathrm{~B} 3$ (1:256 dilution) which detects disaccharide stubs on deglycosylated aggrecan (ICN Flow), ${ }^{25}$ for one hour at ambient temperature before washing $(5 \times 30$ seconds) in blocking buffer. Filters were incubated with the second antibody (goat antimouse immunoglobulin, conjugated with alkaline phosphatase; Promega, Southampton, UK) at 1:500 dilution for one hour, and washed as above. Finally, the blots were developed using the AP colour detection kit (Bio-Rad, Hemel Hempstead, Hertfordshire, UK).

Samples $(1 \mu \mathrm{l})$ for quantitative analysis by dot blot immunoassay were spotted on to dry nitrocellulose filters (Bio-Rad). The filters were incubated for 30 minutes in a humid atmosphere before the blots were processed for $\mathrm{BC} 3$ and $3 \mathrm{~B} 3$ reactivity as described above.

PREPARATION OF CHONDROCYTE AND CARTILAGE EXTRACTS

Chondrocytes were cultured for at least one week before the cell layer was obtained using a cell scraper. The cells were then taken up in approximately one volume of either $50 \mathrm{mM}$ Tris/ $\mathrm{HCl}$, $\mathrm{pH} 7.5$, or $16 \mathrm{mM} 2-(\mathrm{N}-$ morpholino)ethane sulphonic acid (Mes), $\mathrm{pH} 5.5$, containing $0.1 \%$ or $3 \%$ Triton-X 100 (lysis buffers), and freeze-thawed twice. Cell debris was removed by centrifugation at $10000 \times g$ for 10 minutes, and the supernatant was used in the in vitro aggrecanase assay.

Cartilage discs were crushed at $-70^{\circ} \mathrm{C}$ by hitting the frozen tissue, contained in a cooled chamber, with a piston and mallet. The crushed tissue was taken up in approximately one volume of the lysis buffers and extracted as described for chondrocytes.

IN VITRO ASSAY FOR AGGRECANASE ACTIVITY

Before carrying out aggrecanase assays on lysed chondrocytes, crushed cartilage, or concentrated culture medium, the endogenous proteoglycan associated with the cells, tissue, or medium was removed by anion-exchange chromatography. Lysed extracts were loaded on to a Resource- $Q$ column (Pharmacia, Uppsala, Sweden) in either $50 \mathrm{mM}$ Tris/ $\mathrm{HCl}, 1 \mathrm{M}$ $\mathrm{NaCl}, \mathrm{pH} 7.5$, or $16 \mathrm{mM} \mathrm{Mes,} 1 \mathrm{M} \mathrm{NaCl}$, $\mathrm{pH} 5.5$, at $1 \mathrm{ml} / \mathrm{min}$, and protein eluting directly from the column was collected. The high salt concentration precluded the binding of most proteins, other than proteoglycans, to the column. The column flow-through frac- tions were desalted on Sephadex-G25 (Pharmacia) into either $16 \mathrm{mM}$ Tris/ $\mathrm{HCl}, 4 \mathrm{mM}$ $\mathrm{CaCl}_{2}, \mathrm{pH} 7.5$, or $16 \mathrm{mM} \mathrm{Mes,} \mathrm{pH}$ 5.5, before they were assayed for aggrecanase activity.

Aggrecanase assays were carried out in either $16 \mathrm{mM}$ Tris/ $\mathrm{HCl}$ buffer, $4 \mathrm{mM} \mathrm{CaCl}$, $\mathrm{pH} 7.5$ (to detect the activity of putative serine or metalloproteinases), or $16 \mathrm{mM} \mathrm{Mes,} \mathrm{pH} 5.5$, with or without $5 \mathrm{mM}$ cysteine (for the detection of putative cysteine proteinase activity). Bovine nasal cartilage aggrecan at a concentration of $10 \mathrm{mg} / \mathrm{ml}$ was incubated overnight at $37^{\circ} \mathrm{C}$ with $10 \mu \mathrm{l}$ of cell or tissue extract and buffer in a total volume of $50 \mu$ l. Assays were terminated by boiling for five minutes, and the assay mixture was deglycosylated before loading on to filters.

N-TERMINAL SEQUENCE ANALYSIS OF AGGRECAN CORE PROTEIN FRAGMENTS RELEASED INTO THE CULTURE MEDIUM

The cartilage from one nasal septum was prepared essentially as described previously. ${ }^{6}$ The tissue was then divided into two and each half was cultured for five days, with one change of medium, in the presence or absence of $\operatorname{rhTNF} \alpha(3 \mathrm{nM})$. Analyses of the culture media with dimethylmethylene blue ${ }^{22}$ showed that cartilage slices cultured in the presence of TNF released $225 \mathrm{mg}$ of sGAG, whereas only $70 \mathrm{mg}$ was released in the absence of the cytokine. Proteoglycan fragments released into the medium were purified by anion-exchange chromatography on a Q-Sepharose column (Pharmacia) and density gradient centrifugation, ${ }^{23}$ deglycosylated, and then separated by $4-10 \%$ gradient PAGE in the presence of SDS. Following transfer to PVDF membranes, bands were visualised with either antibody $3 \mathrm{~B} 3$, or by silver-staining. For N-terminal sequence analysis, bands were identified while the blot was drying, excised, and core protein fragments were sequenced on a gas phase sequenator. ${ }^{15}$

\section{Results}

IMMUNOLOGICAL DETECTION OF AGGRECANASE CLEAVED AGGRECAN FROM EXPLANT CULTURE MEDIUM USING ANTIBODY BC3

Western blot analysis demonstrated the presence of a number of proteoglycan fragments in cartilage explant culture media (fig 1A). Fragments reacting with $\mathrm{BC} 3$ were detected in media from cartilage explants cultured in the presence or absence of IL-1, TNF, and Ret (fig 1B). This antibody recognises the ARGS neoepitope produced upon cleavage by aggrecanase within the aggrecan interglobular domain. In all cases the strongest signal came from the largest of the fragments, suggesting that this was the major product of aggrecanase activity.

\section{THE HYDROLYSIS OF AGGRECAN BY CARTILAGE} EXPLANTS IN RESPONSE TO TNF

We have shown (fig 1B) that cartilage explants treated with IL-1, Ret or TNF released BC3 reactive aggrecan fragments. The result following IL-1 and Ret treatment was expected, in line with previous reports, ${ }^{6}{ }^{14-17}$ but the production of TNF mediated aggrecanase generated fragments had not previously been formally 


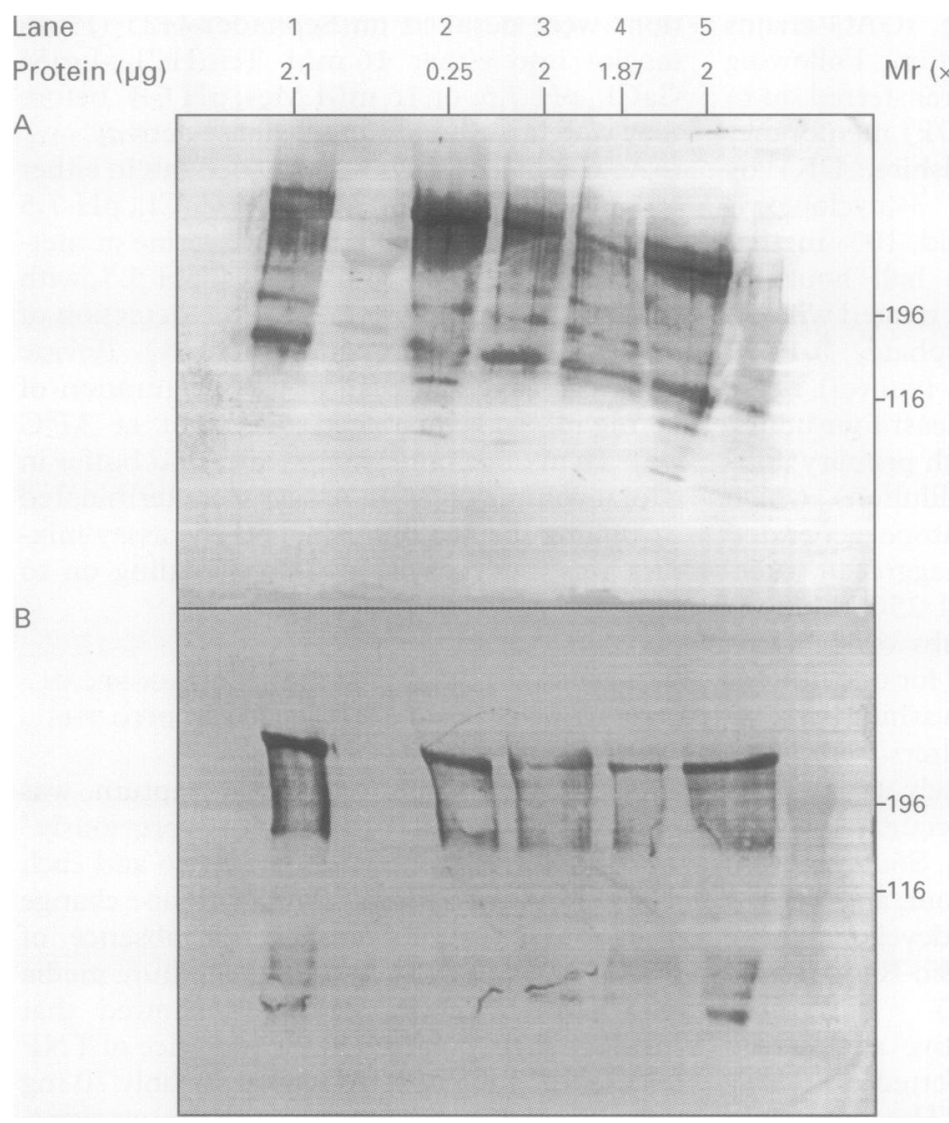

Figure 1 Western blots of aggrecan fragments from cartilage explant culture media probed with $(A)$ antibody $3 B 3$, and $(B)$ antibody BC3. Samples in the numbered tracks were as follows: lane 1, control culture medium; lanes 2 and 5, TNF treated; lane 3, IL-1 treated; lane 4, Ret treated. demonstrated. Therefore, we determined the $\mathrm{N}$-terminal sequences of aggrecan fragments released into the culture medium of $\operatorname{rhNN} \alpha$ treated bovine nasal cartilage explants. Ten fragments gave a clear $\mathrm{N}$-terminal sequence (fig 2 ), with seven having the ARGS N-terminus recognised by $\mathrm{BC} 3$. Two other $\mathrm{N}$-terminal sequences were also found; these were identical to $\mathrm{N}$-terminal sequences previously identified following the treatment of bovine cartilage explants with IL-1 and Ret, ${ }^{6}{ }^{15}$ and result from cleavages within the chondroitin sulphate attachment domain 2 . All three cleavages apparently took place between a glutamic acid residue and an uncharged aliphatic amino acid, in line with the predicted specificity of aggrecanase. We cannot discount the possibility that other proteinases may contribute to aggrecan breakdown, but our data are consistent with aggrecanase being the principal agent responsible for aggrecan breakdown stimulated by TNF, as has been demonstrated previously, following treatment of cartilage explants, with and without IL-1 and Ret.

\section{DEGLYCOSYLATED PROTEOGLYCAN INHIBITS} ENDOGENOUS PROTEOGLYCAN BREAKDOWN We wished to determine whether exogenously added proteoglycan was cleaved when cultured with IL-1 treated nasal cartilage explants. In order to differentiate between endogenous and exogenous proteoglycan we used deglycosylated proteoglycan for these experiments. Removal of the sGAG chains allowed subsequent fractionation by gradient

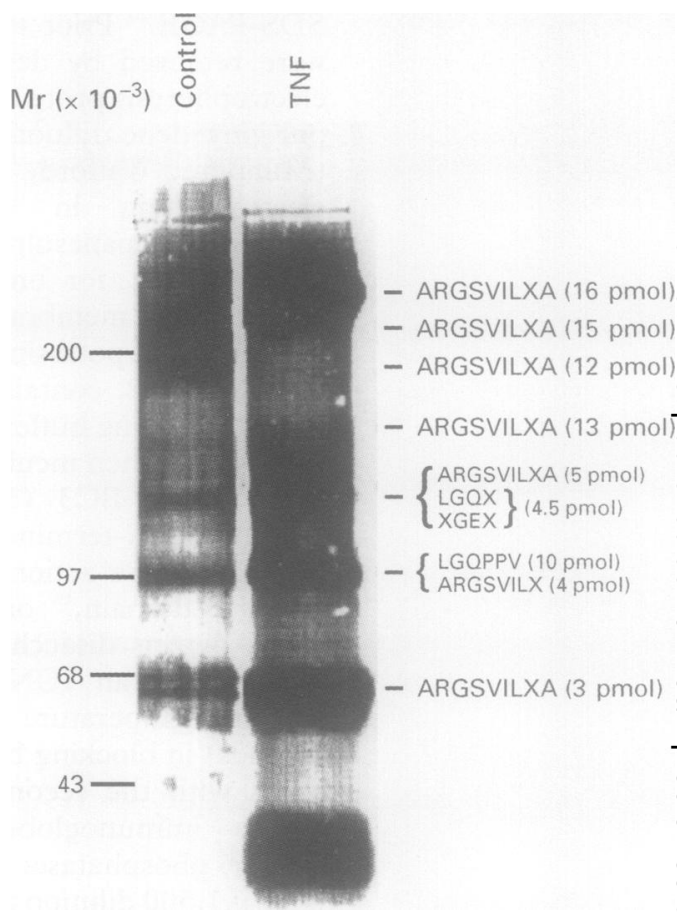

Figure 2 Analysis of aggrecan core protein fragments released into the culture medium of bovine nasal septum cartilage explants with and without treatment with rhTNF. Samples were prepared as described in the Methods section, and separated by gradient PAGE in the presence of SDS. The gel was then silver-stained. For the determination of $N$-terminal sequences the protein bands were transferred to polyvinylidene membranes and their positions identified during filter drying; they were then excised and sequenced. Individual N-terminal sequences are shown, together with the yields of the first residue for the TNF stimulated sample.

PAGE in the presence of SDS, and western blotting, whereas endogenous aggrecan was $\overrightarrow{\bar{O}}$ excluded from entering the gel due to its large ${ }^{3}$ size. We found no evidence of cleavage of deglycosylated exogenous proteoglycan during. a two day culture period in the presence of explants treated with $0.3 \mathrm{nM}$ rhIL-1 $\alpha$. Therewas no appearance of $\mathrm{BC} 3$ reactivity as determined by western blotting (results noto shown). A surprising finding was the dose 3 dependent inhibition of IL-1 stimulated en-윽 dogenous proteoglycan breakdown by thes deglycosylated molecule. The results of aㅡㅡ. representative experiment are shown in table 1 . N The $\mathrm{IC}_{50}$ was $~ 50 \mathrm{nM}(20 \mu \mathrm{g} / \mathrm{ml})$, suggesting $\mathrm{a}$ specific molecular interaction of some kind.

Table 1 The inhibition by exogenous deglycosylated proteoglycan of rhIL1a-stimulated bovine nasal septum cartilage proteoglycan breakdown

\begin{tabular}{|c|c|c|}
\hline $\begin{array}{l}\text { Exogenous } \\
\text { proteoglycan }(\mu \mathrm{g} / \mathrm{ml})\end{array}$ & $\begin{array}{l}{ }_{s} G A G \text { released } \\
(\mu g)\end{array}$ & Inhibition (\%) \\
\hline 0 & 1077 (197) & 0 \\
\hline 0.53 & $675(94)$ & 37 \\
\hline 1.6 & $605(68)$ & 44 \\
\hline 4.8 & $588(73)$ & 45 \\
\hline 14 & $560(51)$ & 48 \\
\hline 29 & $487(74)$ & 55 \\
\hline 115 & $325(52)$ & 70 \\
\hline
\end{tabular}

This is representative of four individual experiments. The actua 6 음 values of sGAG released varied between experiments, but in alf cases there was a dose dependent inhibition by exogenous deglycosylated proteoglycan. In two of the four experiments $100 \%$ inhibition was achieved by $29 \mu \mathrm{g} / \mathrm{ml}$ and $214 \mu \mathrm{g} / \mathrm{ml}$ of deglycosylated aggrecan. In the other two experiments (including the one shown) $100 \%$ inhibition was not attained.

${ }^{\star}$ Values are mean (SEM). The basal level of release in the absence of rhIL1 $\alpha$, of $206 \mu \mathrm{g}$, was subtracted from all other values. 


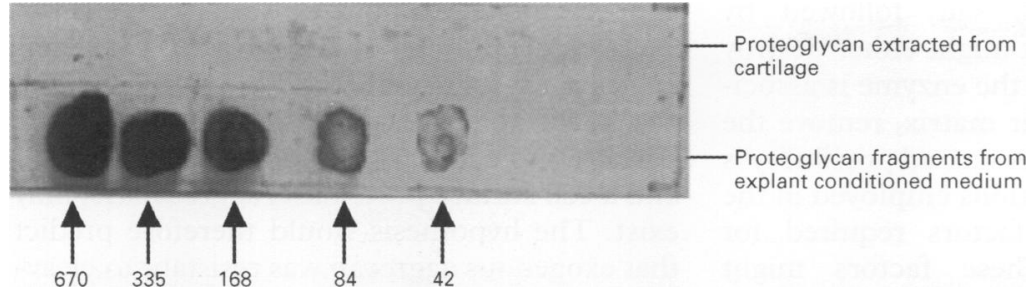

Figure 3 Dot blot immunoassay of aggrecan fragments obtained from cartilage explant culture media and extracted from cartilage. Samples $(1 \mu \mathrm{l})$, the proteoglycan contents of which are shown (in $n g$ ), were spotted on to the filter and probed with antibody BC3.

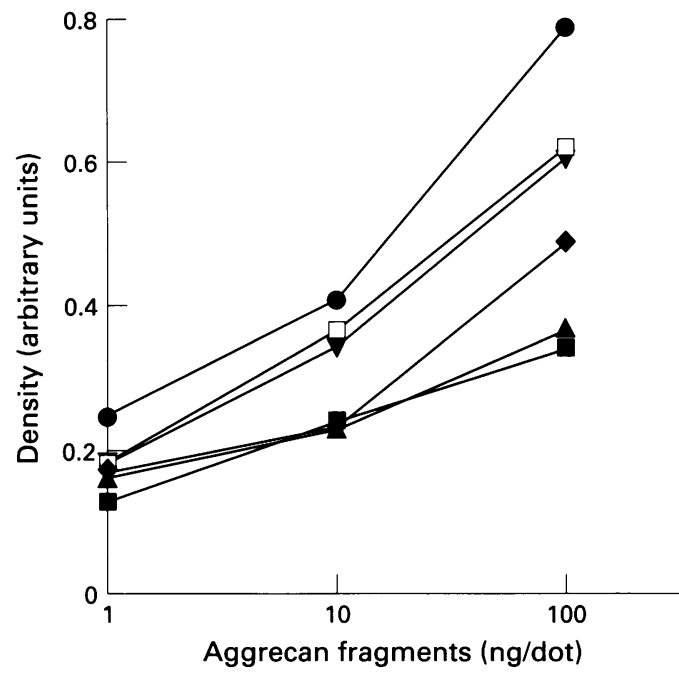

Figure 4 Semi-logarithmic standard curves for the quantitative detection of $B C 3$ reactive aggrecan fragments. The readings were obtained by densitometric scanning of dots that had been loaded with increasing amounts of aggrecan fragments obtained from cartilage explant conditioned media (horizontal axis). The experiments differed in terms of the amounts of antibody that were used: - BC3 1:1000, second antibody 1:1000; BC3 1:1000, second antibody 1:500; $\bullet B C 3$ 1:1000, second antibody 1:250; $\nabla$ BC3 1:500, second antibody 1:1000; $\square$ BC3 1:500, second antibody 1:500;BC3 1:500, second antibody $1: 250$.

DOT BLOT IMMUNOASSAYS FOR AGGRECANASE CLEAVED AGGRECAN

We used aggrecanase generated aggrecan fragments to develop a dot blot assay using BC3. The assay specifically detected aggrecanase cleaved fragments of aggrecan but did not detect uncleaved aggrecan from bovine nasal cartilage (fig 3). The lack of BC3 reactivity in our preparation of aggrecan extracted from bovine cartilage was an important prerequisite for the aggrecanase assay in which uncleaved exogenous aggrecan acts as the substrate. Densitometry of the signals produced from the dot blots (fig 4) indicated that there was a dose response up to at least $100 \mathrm{ng}$ of sGAG (estimated by the dye-binding assay ${ }^{22}$ before deglycosylation), equivalent to $\sim 0.25 \mathrm{pmol}$ aggrecan, with $1 \mathrm{ng}$ being the limit of detection. The relation between the amount of aggrecan fragments added to a dot and the subsequent density was not linear, but when the $\log$ of the dose was plotted against

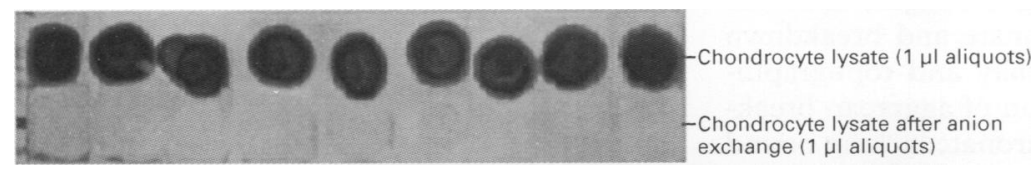

Figure 5 Dot blot immunoassay of chondrocyte lysates before and after anion-exchange chromatography. The filter was probed with antibody $B C 3$. the density (fig 4) an approximate straight line was produced. The sensitivity of the assay (but not the useful range) depended on the concentrations of $\mathrm{BC} 3$ and the second antibody.

\section{AGGRECANASE ASSAYS ON CHONDROCYTE}

LYSATES AND CULTURE MEDIA

Crushed cartilage extracts, lysed chondrocytes, and conditioned media from chondrocyte cultures were assayed for aggrecanase activity. Using both western or dot blots, BC3 reactivity could not be detected following incubation of intact aggrecan with extracts, lysates, or conditioned medium under two sets of conditions chosen for the manifestation of serine, cysteine and metalloproteinase activities. Increasing the concentration of Triton X-100 in the lysis buffer from $0.1-3 \%$, a concentration that is known to solubilise a membrane-bound metalloproteinase, ${ }^{26}$ did not lead to detection of $\mathrm{BC} 3$ reactivity associated with the supernatants. Aggrecanase activity was not detected in vitro despite the presence of endogenous BC3 reactive fragments in the chondrocyte lysates and the conditioned medium (fig $1 \mathrm{~B}$, fig 5), which were removed by ion-exchange chromatography prior to assay (fig 5).

\section{Discussion}

The release from cartilage cultures of aggrecan fragments having the sequence ARGS at the $\mathrm{N}$-terminus, and the presence of similar fragments in synovial fluid has been reported. ${ }^{6}{ }^{12-18}$ The existence of this $\mathrm{N}$-terminus is consistent with a large proportion of hydrolysed aggrecan being produced by an unidentified glutamyl endopeptidase, termed aggrecanase. We have confirmed that a monoclonal antibody recognising the ARGS neoepitope specifically detects aggrecanase cleaved fragments of aggrecan in the culture media of cartilage explants treated with IL-1 or Ret, and shown for the first time the presence of aggrecanase generated aggrecan fragments in cultures treated with TNF.

One of the aims of this study was to develop an in vitro assay for aggrecanase activity. We were able, specifically, to detect aggrecanase cleaved aggrecan using BC3 in a dot blot assay. The ARGS neoepitope was detected in proteoglycan fragments obtained from cartilage conditioned culture medium and in crude extracts obtained after lysis of chondrocyte cell layers (where the fragments may have been cell associated or intracellular). However, exogenous deglycosylated aggrecan was not cleaved by cartilage explant cultures. In addition, samples of lysed chondrocytes, crushed and extracted samples from cartilage, and explant culture media did not cleave aggrecan to yield BC3 reactivity under conditions designed for the assay of three classes of proteolytic enzyme that are implicated in proteoglycan breakdown. ${ }^{6}{ }^{27}$

A number of factors may be responsible for our failure to detect aggrecanase activity from extracts of cells which are producing aggrecanase cleaved aggrecan in culture. First, in order to carry out the in vitro assay we removed endogenous aggrecan fragments from the cultures; this was achieved by anion-exchange 
chromatography in high salt, followed by desalting. Such treatment might either destroy aggrecanase activity or, if the enzyme is associated with the extracellular matrix, remove the enzyme from the extract. A second possibility is that the incubation conditions employed in the assay did not include factors required for aggrecanase activity. These factors might include potential activators of the proteinase, which may exist largely as an inactive proenzyme, or putative cofactors required for enzyme activity. Finally, the assay substrate, uncleaved aggrecan removed from its native cartilage matrix, may be in a form which is not recognised by aggrecanase.

The lack of aggrecanase activity in cartilage conditioned culture medium may indicate that the activity is cell or tissue associated, and the inability of cartilage explants to cleave exogenous deglycosylated aggrecan suggests that the activity of aggrecanase may be a tightly regulated cell surface event. Recent evidence points to aggrecanase being a metalloproteinase, but not one of the known members of the matrix metalloproteinase family. ${ }^{11}{ }^{28} \mathrm{Mem}-$ brane bound metalloproteinases that are closely related to the matrix metalloproteinases, such as the reprolysins or adamalysins,${ }^{29}$ have been identified in mammals. ${ }^{26} 30$

The resistance of exogenous deglycosylated aggrecan to hydrolysis by aggrecanase, and the inhibitory activity of exogenous aggrecan, may suggest a role for sGAG chains in the regulation of aggrecan breakdown. We cannot, however, discount the possibility that our preparations of deglycosylated aggrecan contained a component other than aggrecan that was inhibiting endogenous proteoglycan breakdown, although we simply added back the components of our explant system that were present during the breakdown of endogenous proteoglycan. There has been a report of the inhibition of cartilage explant proteoglycan breakdown by exogenously added hyaluronate ${ }^{31}$; we did not take any steps to remove hyaluronate from our aggrecan preparation, and this molecule could, therefore, have contributed to the inhibition of proteoglycan breakdown in our experiments. However, the $\mathrm{IC}_{50}$ for the effect of exogenous hyaluronate was $\sim 500 \mu \mathrm{g} / \mathrm{ml},{ }^{31}$ whereas our preparation of deglycosylated aggrecan was much more potent, with an $\mathrm{IC}_{50}$ of $\sim 20 \mu \mathrm{g} / \mathrm{ml}$.

The hydrolysis of aggrecan may be regulated by association with cell surface components. For instance, it is known that binding, internalisation, and breakdown of hyaluronate is mediated by its cell surface receptor, CD44, ${ }^{32}$ and that the $t_{0.5}$ for turnover of both hyaluronate and aggrecan is similar. ${ }^{33}$ As previously noted, ${ }^{34}$ this apparent co-ordinate regulation, and the likelihood that hyaluronate destined for breakdown will be associated with numerous aggrecan molecules, might suggest that the internalisation of hyaluronate and breakdown of aggrecan are functionally and topographically linked. The inhibition of aggrecan breakdown by exogenous hyaluronate lacking bound aggrecan $^{32}$ could then be explained by competition for CD44. It is known that chondrocytes express the haematopoietic variant of CD44 ${ }^{35}$ and that the number of cell surface CD44 molecules is up-regulated by IL- 1 treatment ${ }^{36}$ that also leads to increased aggrecan breakdown. Thus, a molecular association between CD44 and a cell surface proteinase, aggrecanase, may exist. The hypothesis would therefore predict으 that exogenous aggrecan was resistant to cleav- 0 age because it was not bound to CD44 via hyaluronate, rather than because it was deglycosylated.

Supported mainly by grants from the Arthritis and Rheumatism Supported mainly by grants from the Arthritis and Rheumatism Clare Hughes, School of Molecular and Medical Biosciences, $\vec{\nabla}$ University of Wales, Cardiff for provision of the monoclonal University of Wales, Cardiff for provision of the monoclonal Ltd, Greenford, UK, Dr Steven Dower, Immunex, Seattle, Washington, USA, and Dr E Amento, Genentech Inc, Boulder, Colorado, USA for generous gifts of cytokines.

1 Kempson GE, Tuke MA, Dingle JT, Barrett AJ, Horsfield $\mathrm{PH}$. The effects of proteolytic enzymes on the mechanical properties of adult human articular cartilage. Biochim Bio-z phys Acta 1976;428:741-60.

2 Hollander AP, Atkins RM, Eastwood DM, Dieppe PA, O Elson CJ. Human cartilage is degraded by rheumatoid $\omega$ arthritis synovial fluid but not by recombinant cytokines in vitro. Clin Exp Immunol 1991;83:52-7.

3 vitro. Clin Exp Immunol 1991,83:52-7. breakdown of articular cartilage in organ culture. Arthritis Rheum 1977:20:1359-71.

4 Saklatvala J, Pilsworth LMC, Sarsfield SJ, Gavrilovic J, Heath JK. Pig catabolin is a form of interleukin 1. Cartilage and bone resorb, fibroblasts make prostaglandin and collagenase, and thymocyte proliferation is augmented in response to one protein. Biochem $\mathcal{F} 1984 ; 224: 461-6$.

5 Saklatvala J. Tumour necrosis factor alpha stimulatese resorption and inhibits synthesis of proteoglycan in cartilage. Nature 1986;322:547-9.

6 Buttle DJ, Handley CJ, Ilic MZ, Saklatvala J, Murata M, Barrett AJ. Inhibition of cartilage proteoglycan release by a乏 specific inactivator of cathepsin B and an inhibitor of matrix metalloproteinases. Evidence for two converging matrix metalloproteinases. Evidence for two converging pathways of chondrocyte-mediated proteoglycan degrada-o
tion. Arthritis Rheum 1993;36:1709-17.

7 Buttle DJ, Bramwell H, Hollander AP. Proteolytic mechanisms of cartilage breakdown-a target for arthritis therapy? F Clin Pathol: Mol Pathol 1995;48:M167-77.

8 Nixon JS, Bottomley KMK, Broadhurst MJ, Brown PA, Johnson WH, Lawton G, et al. Potent ollagenase inhibitors? prevent interleukin 1-induced cartilage degradation in vitro. Int $¥$ Tiss Reac 1991;13:237-43.

9 Andrews HJ, Plumpton TA, Harper GP, Cawston TE. A synthetic peptide metalloproteinase inhibitor, but not Timp, prevents the breakdown of proteoglycan withinTimp, prevents the breakdown of proteoglycan withino
articular cartilage in vitro. Agents Actions 1992;37:147-54.3

10 Seed MP, Ismail S, Cheung CY, Thomson TA, Gardner $\mathrm{CR}$, Atkins RM, et al. Inhibition of interleukin 1 betaO induced rat and human cartilage degradation in vitro by the metalloproteinase inhibitor U27931. Ann Rheum Dis 1993; 52:37-43.

11 Brown CJ, Rahman S, Morton AC, Beauchamp CL, Bramwell $\mathrm{H}$, Buttle DJ. Inhibitors of collagenase but not of gelatinase reduce cartilage explant proteoglycan breakdown despite only low levels of matrix metalloproteinasen down despite only low levels of matrix metalloproteinase $N$

12 Sandy JD, Flannery CR, Neame PJ, Lohmander LS. The structure of aggrecan fragments in human synovial fluid.C Evidence for the involvement in osteoarthritis of a noveln proteinase which cleaves the Glu373-Ala374 bond in the $\omega$ interglobular domain. $\mathcal{F}$ Clin Invest 1992;89:1512-6.

13 Lohmander LS, Neame PJ, Sandy JD. The structure of aggrecan fragments in human synovial fluid. Evidence thate aggrecanase mediates cartilage degradation in inflammtory joint disease. Arthritis Rheum 1993;36:1214-22.

14 Sandy JD, Neame Sandy JD, Neame PJ, Boynton RE, Flannery CR. Catabolism of aggrecan in cartilage explants. $\mathcal{F}$ Biol Chem 5 Ilic $M Z$,

Ilic MZ, Handley CJ, Robinson HC, Mok MT. Mechanism of catabolism of aggrecan by articular cartilage. Arch $\frac{\mathbb{\Phi}}{\text { Biochem Biophys 1992;294:115-22. }}$
Loulakis P Shrikhande A Davis G, Magnilia

6 Loulakis P, Shrikhande A, Davis G, Magnilia CA.O $\mathrm{N}$-terminal sequence of proteoglycan fragments isolated from medium of interleukin-1 treated articular cartilage? cultures. Putative site(s) of enzymic cleavage. Biochem 1992;284:589-93.

17 Lark MW, Gordy JT, Weidner JR, Ayala J, Kimura JH, Wil liams HR et al. Cell-mediated catabolism of aggrecan. Evidence that cleavage at the aggrecanase cleavage site(Glu373-Ala374) is a primary event in proteolysis of the interglobular domain. $\mathscr{f}$ Biol Chem 1995;270:2550-6.

18 Plaas AHK, Sandy JD. A cartilage explant system for studies on aggrecan structure, biosynthesis and catabolism in discrete zones of the mammalian growth plate. Matrix 1993;13:135-47.

19 Hughes CE, Caterson B, Fosang AJ, Roughley PJ, Mort JS. Monoclonal antibodies that specifically recognise 
neoepitope sequences generated by aggrecanase and matrix metalloproteinase cleavage of aggrecan: application to catabolism in situ and in vitro. Biochem $\mathcal{f}$ 1995;305:799 804.

20 Buttle DJ, Saklatvala J, Tamai M, Barrett AJ. Inhibition of interleukin 1-stimulated cartilage proteoglycan degradation by a lipophillic inactivator of cysteine endopeptidases. tion by a lipophillic inactivat
Biochem $\mathcal{f} 1992 ; 281: 175-7$.

21 Holtzer H, Abbot J, Lash J, Holtzer S. The loss of phenotypic traits by differentiated cells in vitro. I. Dedifferentiation of cartilage cells. Proc Natl Acad Sci USA 1960;46:1533-42.

22 Farndale RW, Buttle DJ, Barrett AJ. Improved quantitation and discrimination of sulphated glycosaminoglycans by use of dimethylmethylene blue. Biochim Biophys Acta 1986 883:173-7.

23 Handley CJ, Buttle DJ. Assay of proteoglycan degradation. Methods Enzymol 1995;248:47-58.

24 Laemmli UK. Cleavage of structural proteins during assembly of the head of bacteriophage T4. Nature 1970;227:6805.

25 Couchman JR, Caterson B, Christner JE, Baker JR. Mapping by monoclonal antibody detection of glycosaminoglycans in connective tissues. Nature 1984;307 650-2.

26 Howard L, Glynn P. Membrane-associated metalloproteinase recognized by characteristic cleavage of myelin basic protein: assay and isolation. Methods Enzymol 1995;248: 388-95.

27 Bunning RAD, Crawford A, Richardson HJ, Opdenakker G, van Damme J, Russell RGG. Interleukin 1 preferentially vatimulates the production of tissue-type plasminogen activator by human articular chondrocytes. Biochim Biophys Acta $1987 ; 924: 473-82$.
28 Kozaci LD, Buttle DJ, Hollander AP. Degradation of type II collagen, but not proteoglycan, correlates with matrix metalloproteinase activity in cartilage explant cultures. Arthritis Rheum 1996;40: 164-74.

29 Rawlings ND, Barrett AJ. Evolutionary families of metallopeptidases. Methods Enzymol 1995;248:183-228.

30 McKie N, Dallas DJ, Edwards T, Apperley JF, Russell RGG, Croucher PI. Cloning of a novel membrane-linked metalloproteinase from human myeloma cells. Biochem $\mathcal{f}$ metalloproteinase

31 Morris EA, Wilcon S, Treadwell BV. Inhibition of interleukin 1-mediated proteoglycan degradation in bovine articular cartilage explants by addition of sodium hyaluronate. Am ₹ Vet Res 1992;53:1977-82.

32 Culty $M$, Nguyen HA, Underhill CB. The hyaluronan receptor (CD44) participates in the uptake and degradation of hyaluronan. $f$ Cell Biol 1992;116:1055-62.

$33 \mathrm{Ng} \mathrm{CK}$, Handley CJ, Preston BN, Robinson HC. The extracellular processing and catabolism of hyaluronan in cultured adult articular cartilage explants. Arch Biochem Biophys 1992;298:70-9.

34 Ng CK, Handley CJ, Preston BN, Robinson HC, Bolis S, Parker G. Effect of exogenous hyaluronan and hyaluronan oligosaccharides on hyaluronan and aggrecan synthesis and catabolism in adult articular cartilage explants. Arch Biochem Biophys 1995;316:596-606.

35 Salter DM, Godolphin JL, Gourlay MS, Lawson MF, Hughes DE, Dunne E. Analysis of human articular chondrocyte CD44 isoform expression and function in health and disease. $\mathcal{F}$ Pathol 1996;179:396-402.

36 Chow G, Knudson CB, Homandberg G, Knudson W. Increased expression of CD44 in bovine articular chondrocytes by catabolic cellular mediators. $f$ Biol Chem cytes by catabolic
$1995 ; 270: 27734-41$. 